
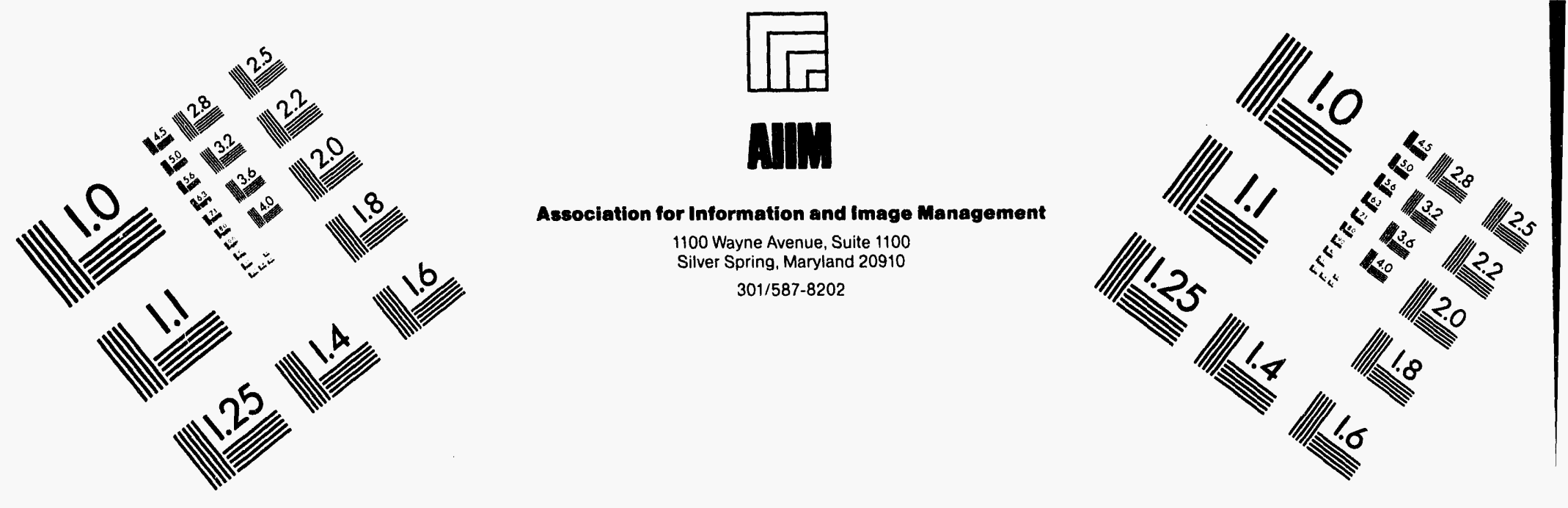

\title{
Centimeter
}

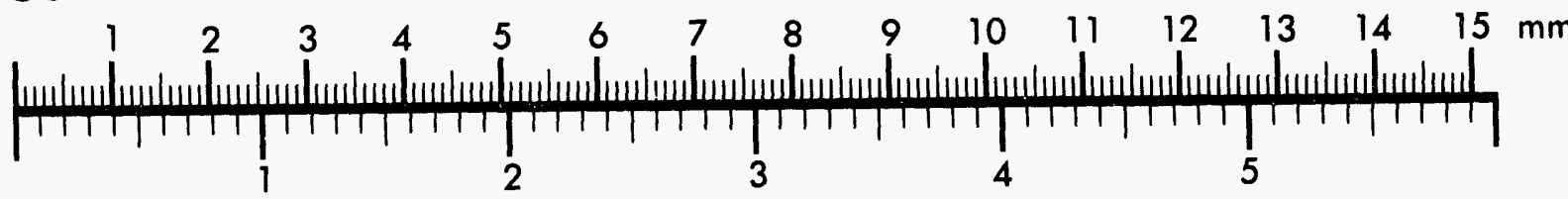
Inches
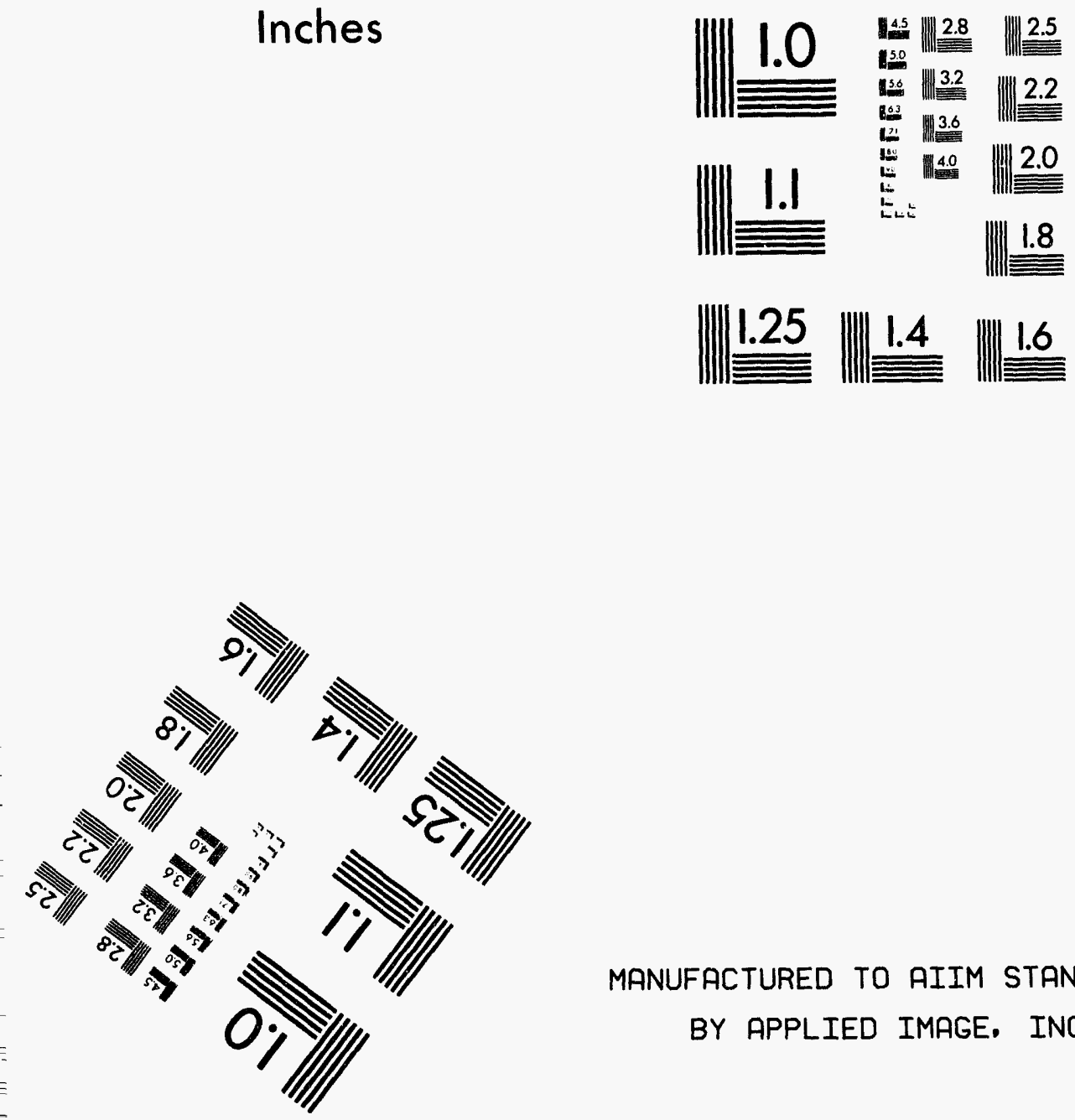

MANUFACTURED TO AIIM STANDARDS

BY APPLIED IMAGE. INC.

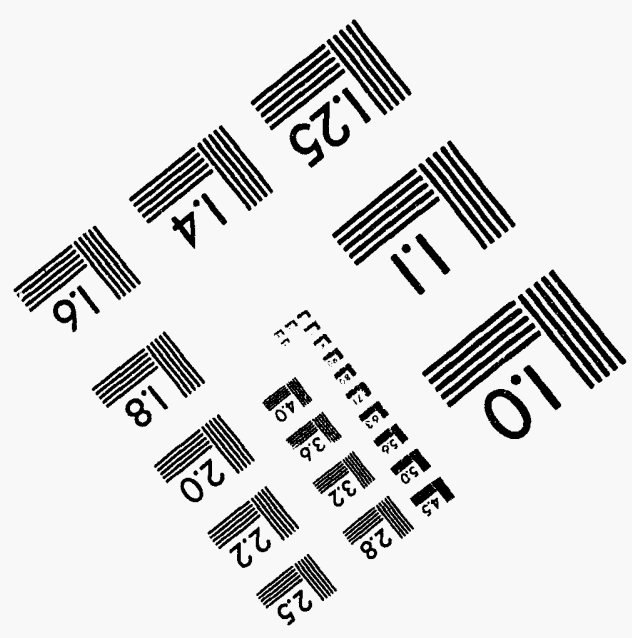



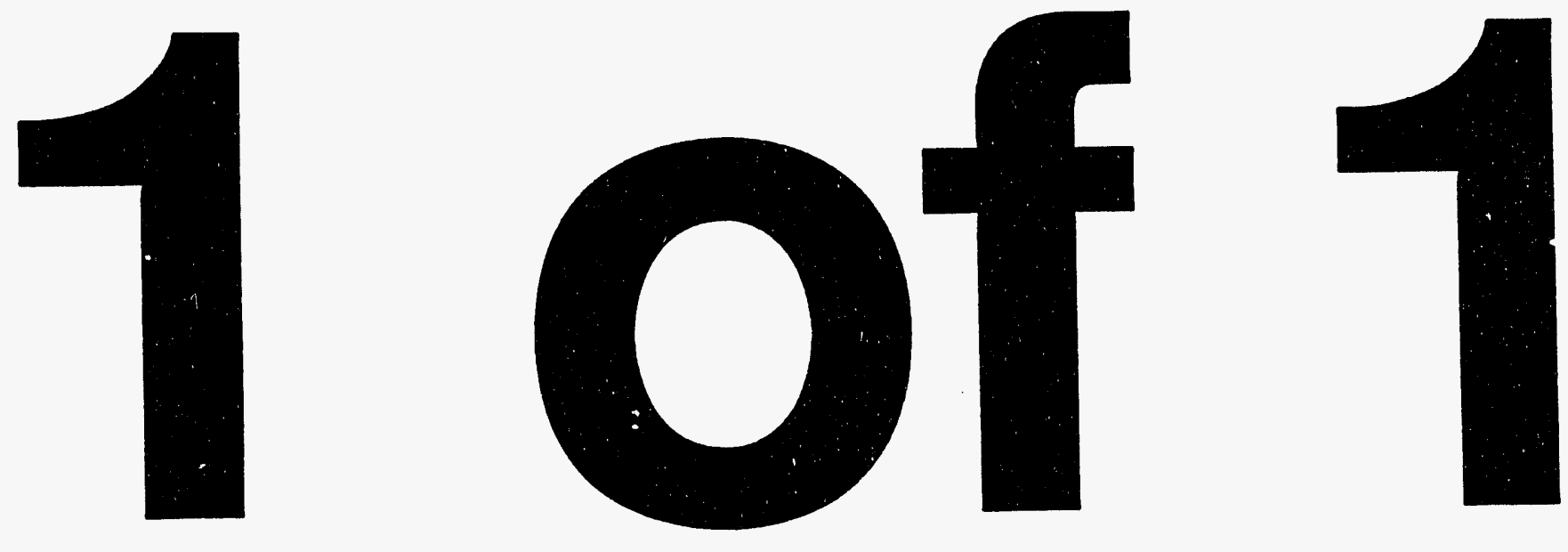


\section{Mixed-Sputter Deposition of Ni-Ti-Cu Shape Memory Films}

P. Krulevitch, P.B. Ramsey,-D.M. Makowiecki, A.P. Lee, and M.A. Northrup

Lawrence Livermore National Laboratory, P.O. Box 808, Livermore CA 94551

G.C. Johnson

Dept. of Mechanical Engineering, University of California, Berkeley, CA 94720

$\mathrm{Ni}-\mathrm{Ti}-\mathrm{Cu}$ shape memory films were mixed-sputter deposited from separate nickel, titanium, and copper targets, providing increased compositional flexibility. Shape memory characteristics, examined for films with 7 at.\% $\mathrm{Cu}$ and 41-51 at.\% $\mathrm{Ti}$, were determined with temperature controlled substrate curvature measurements, and microstructure was studied with transmission electron microscopy. The Ni-Ti-Cu films were found to have shape memory properties comparable to bulk materials, with transformation temperatures between 20 and $62^{\circ} \mathrm{C}$, a $10-13^{\circ} \mathrm{C}$ hysteresis, and up to $330 \mathrm{MPa}$ recoverable stress. 


\section{Mixed-Sputter Deposition of Ni-Ti-Cu Shape Memory Films}

\section{INTRODUCTION}

Shape memory alloys (SMA's), named for their ability to recover large plastic deformation upon heating, have been well characterized in bulk form and have been employed in numerous macro-applications, most notably as dental archwire, heat sensitive transducers, and high-strength fasteners. ${ }^{1,2}$ More recently, interest has arisen in shape memory films for use as actuating members in silicon based micro-electromechanical systems $\mathrm{s}^{3,4}$ and for micro-robotics applications. ${ }^{5,6}$ Several investigations into the properties of NiTi SMA films have been conducted, using sputtering $^{3-11}$ or laser ablation ${ }^{12}$ of single Ni-Ti alloy targets, with the intention of attaining films with the same composition and properties as the well characterized bulk target material. Although these techniques produce relatively uniform films, they allow for little flexibility in terms of composition, which is well known to have a very strong influence on the resulting shape memory behavior. For example, increasing the atomic percentage of nickel by $1 \%$ from an equi-atomic ratio of Ni:Ti lowers the martensitic start temperature, $M_{s}$, from 50 to $-100{ }^{\circ} \mathrm{C}{ }^{13}$ Furthermore, the composition for optimum shape memory properties in a film may vary from that of bulk alloys due to the small grain sizes, surface effects, and plane stress conditions associated with films. In the study presented here, Ni-Ti-Cu SMA films were mixed-sputter deposited, an alternative deposition technique which allows for greater compositional flexibility, with the addition of copper for improved shape memory properties.

A thermally induced crystalline phase change from a ductile martensite to a high strength austenite is responsible for the shape memory effect exhibited by the NiTi alloy. Substitution of between 5 and 15 at\% $\mathrm{Cu}$ for $\mathrm{Ni}$ in the normally equi-atomic $\mathrm{Ni}-\mathrm{Ti}$ system is known to stabilize the shape memory effect in bulk alloys, significantly reducing the extreme sensitivity of the transformation temperature to slight changes in composition. ${ }^{14}$ Copper also serves to decrease the shape memory hysteresis width ${ }^{15,16}$ and lower the martensitic yield stress, ${ }^{17}$ allowing for faster switching times and lower resetting forces in shape memory actuators. Previous work on Ni-Ti$\mathrm{Cu}$ films has been conducted by Chang et al., ${ }^{18-20}$ using multi-layers sputtered by alternating 
between a $\mathrm{Ni}_{45} \mathrm{Ti}_{50} \mathrm{Cu}_{5}$ and pure titanium target to compensate for titanium loss due to preferential sputtering of the alloy target. While this approach increases compositional control, it may lead to local inhomogeneities in the form of $\mathrm{Ti}_{2} \mathrm{Ni}_{\mathrm{i}}$ or $\mathrm{Ti}_{4} \mathrm{Ni}_{2} \mathrm{O}_{\mathrm{x}}$ precipitates which were observed both in the grain interiors and at the boundaries after a one hour anneal at $650^{\circ} \mathrm{C} .{ }^{20}$ The same group has also investigated ion beam enhanced deposition (IBED) techniques for controlling residual stresses in Ni-Ti-Cu films. ${ }^{21}$

\section{EXPERIMENTAL PROCEDURES}

$\mathrm{Ni}-\mathrm{Ti}-\mathrm{Cu}$ films were dc magnetron mixed-sputter deposited from individually powered $\mathrm{Ni}$, $\mathrm{Ti}$, and $\mathrm{Cu}$ targets (all of $99.9 \%$ purity). The three 1.3" diameter "mini" sources, designed for compact, uniform sputter deposition, ${ }^{22}$ were mounted in a close-packed triangular fashion with approximately 4" between the targets and substrate. The films were deposited in a high vacuum chamber $\left(0.5 \times 10^{-8}-10^{-7}\right.$ Torr base pressure $)$ in $8 \mathrm{~m}$ Torr argon onto heated $4 "(100\}$ silicon substrates to produce as-deposited crystalline films and to reduce oxygen contamination, which is known to inhibit the shape memory effect. ${ }^{4,23}$ Thermocouples were mounted directly on the wafer surface to monitor the deposition temperature. The initial wafer temperature was $460^{\circ} \mathrm{C}$, and sputtering caused a steady state increase in the substrate temperature of $90^{\circ} \mathrm{C}$ after $10 \mathrm{~min}$ utes. Substrate heating has been shown to effectively produce as-deposited NiTi SMA films for temperatures as low as $350^{\circ} \mathrm{C}$ (with an initial deposition temperature of $460^{\circ} \mathrm{C}$ ). ${ }^{9}$ Deposition time was 30 minutes for all runs with resulting film thicknesses of approximately $1.0 \mu \mathrm{m}$.

Using the mixed-sputtering approach, the film composition varied gradually over the substrate, making it possible to study shape memory properties corresponding to a range of compositions. The 4" wafers were diced into $20 \times 20 \mathrm{~mm}$ squares, as shown in Fig. 1, and the individual dies were characterized in terms of composition and shape memory properties. Rutherford backscattering (RBS) was performed to analyze film composition, with an estimated uncertainty of 1 at.\%, using a piece of $3 / 8 " \mathrm{Ni}_{50.29} \mathrm{Ti}_{49.71}$ rod for a calibration standard. The shape memory effect was characterized by measuring substrate curvature as a function of temperature.

Curvature measurements were made on the individual dies over the temperature range 24 
to $100^{\circ} \mathrm{C}$ using a Tencor FLX-2320 laser system. The curvature test provides considerable information about the SMA films, including transformation temperatures, recoverable stress, thermal residual stress, total residual stress, and the martensitic yield stress. The temperature was ramped at $2 \%$ minute and $25 \mathrm{~mm}$ scans were made along the diagonal of each die. Film stress, $\sigma_{\mathrm{f}}$, is inversely proportional to the substrate radius of curvature, $\rho$, and is given by the well known Stoney equation, modified for a bi-axial stress state, ${ }^{24}$

$$
\sigma_{\mathrm{f}}=\frac{1}{6} \frac{\mathrm{E}_{\mathrm{s}}}{1-v_{\mathrm{s}}} \frac{\mathrm{t}_{\mathrm{s}}^{2}}{\mathrm{t}_{\mathrm{f}}} \frac{1}{\rho},
$$

where $\mathrm{E}$ is the Young's modulus, $\mathrm{V}$ is the Poisson's ratio, $\mathrm{t}$ is thickness, the subscripts $\mathrm{s}$ and $\mathrm{f}$ refer to substrate and film, respectively. For $\{100\}$-oriented silicon, the bi-axial modulus $E /(1-V)$ is transversely isotropic, ensuring spherical deformation of the substrate. ${ }^{25}$ The wafer curvature before film deposition, measured with an interference microscope, was found to correspond to a stress of less than $10 \mathrm{MPa}$ for a one $\mu \mathrm{m}$ thick film. Based on this result, curvature of the individual dies was assumed to be due to stress in the film only, and any initial curvature was neglected.

Plan view specimens for transmission electron microscopy (TEM) study were prepared by mechanically polishing and ion mill thinning, and were examined in a JEOL JEM 200CX, operating at $200 \mathrm{kV}$.

\section{RESULTS AND DISCUSSION}

Sputtering with the power ratio $200 \mathrm{~W}$ Ti:70 W Ni:10 W Cu produced a film which adhered well to the silicon substrate and exhibited the shape memory effect in the titanium-rich zone of the wafer, as depicted in Fig. 1. The film had a uniform copper concentration of 7 at.\%. Curvature results for four dies from this film are shown in Fig. 2, and Table I summarizes the film compositions and shape memory characteristics of the individual dies.

A generic stress vs. temperature curvature plot appears in Fig. 3, illustrating how the shape memory film properties are determined. These properties are influenced strongly by the magnitude and distribution of residual stress in the high strength, high temperature austenitic phase. During the deposition, which occurs near $550^{\circ} \mathrm{C}$, intrinsic stresses develop. When the sub- 
strate cools after the deposition, a tensile thermal stress also arises due to the large difference in expansion coefficients between the film and substrate. The magnitude of the thermal stress, $\sigma_{\text {th }}$, can be determined from the slope of the stress vs. temperature curve above the martensitic start temperature, $M_{s}$, using the equation

$$
\sigma_{\mathrm{th}}=\left(\mathrm{T}_{\mathrm{dep}}-\mathrm{T}\right) \frac{\Delta \sigma}{\Delta \mathrm{T}}
$$

From the slope of the data shown in Fig. 2, the thermal residual stress is $+440 \mathrm{MPa}$, cooling from a deposition temperature of $550^{\circ} \mathrm{C}$ to $\mathrm{T}=53^{\circ} \mathrm{C}$. Comparing this value with the curvature behavior of the non-transforming films, which have total residual stresses of $+580 \mathrm{MPa}$ at $53^{\circ} \mathrm{C}$, the intrinsic residual stress is approximately $+140 \mathrm{MPa}$, neglecting stress relaxation.

Just before cooling through $\mathrm{M}_{\mathrm{S}}$, the residual stress reaches its maximum value. (The actual value of $\mathbf{M}_{\mathrm{S}}$ depends on the magnitude of residual or externally applied stresses, and a stress rate of $10 \mathrm{MPa} /$ degree has been reported for a NiTi-10\% $\mathrm{Cu}$ bulk alloy ${ }^{13}$ ). Further cooling results in the onset of the martensitic transformation, and the residual stress in the film begins to relax via formation and alignment of twins. ${ }^{26}$ Relaxation continues with cooling until the magnitude of the stress drops below the lower martensitic yield stress, $\sigma_{y(m)}$, or the amount of strain relaxed exceeds the maximum strain which can be easily (and reversibly) absorbed by the martensitic phase. Because the curvature vs. temperature plot is horizontal just below the martensite finish temperature, $\mathrm{M}_{\mathrm{f}}$, this stress corresponds to $\sigma_{\mathrm{y}(\mathrm{m})}$. From Fig. 2, the lower martensitic yield stress for the film with 51 at.\% titanium is $120 \mathrm{MPa}$, which agrees well with room temperature measurements made on a bulk Ni-Ti-Cu alloy containing $42.8 \% \mathrm{Ni}, 51.3 \% \mathrm{Ti}$, and $5.9 \% \mathrm{Cu}(\mathrm{at} . \%) .{ }^{27}$

Subsequent heating of the film above the austenite start temperature, $A_{S}$, results in recovery of the residual stress. If the residual stress is too large, some non-recoverable deformation will occur due to slip instead of twinning, or decohesion at the film/substrate interface. This is evident in Fig. 2, which shows that portions of the film that exhibit shape memory do not recover the total residual stress. For the film containing 51 at. $\% \mathrm{Ti}$, the stress of $+450 \mathrm{MPa}$ at $53^{\circ} \mathrm{C}$ results from the non-recoverable relaxation of $130 \mathrm{MPa}$ residual stress. However, the shape of the hysteresis loop 
remains stable with additional thermal cycling, as seen by the data in Fig. 2 .

For an unreleased film, the recoverable stress, $\sigma_{\text {rec }}$, is given by the difference between the stress at the austenite finish temperature, $A_{f}$, and $\sigma_{y(m)}$, as shown in Fig. 3. The recoverable stress is similar to the stress generated in constrained recovery for a tensile test, although the curvature test measures the recoverable stress for the second constrained transformation cycle, the first having occurred upon cooling after the deposition. The recoverable stresses in the Ni-Ti-Cu films with titanium contents between 47 and 51 at.\% (see Table I) compare well with the Ni-Ti films studied by Miyazaki and Nomura, which showed the perfect shape memory effect (a closed hysteresis loop) for externally applied stresses below about $300 \mathrm{MPa} .^{11}$

A film which has been freed from the substrate will deform in response to the recovered residual stress, expanding or contracting into its shape-set configuration. Curling has been observed in released Ni-Ti films upon heating, ${ }^{3,6,8}$ resulting from through-thickness gradients in residual stress or microstructure. For example, a silicon-rich layer at the SMA/silicon interface will not exhibit the shape memory effect, and will induce curvature when the remainder of the film expands or contracts. Such a layer has been detected in annealed NiTi films on silicon, ${ }^{9}$ and a similar non-transforming layer has been observed in Ni-Ti films on $\mathrm{SiO}_{2} \cdot{ }^{10}$ The RBS data for the $\mathrm{Ni}-\mathrm{Ti}-\mathrm{Cu}$ films studied here did not show evidence of silicide formation, although silicon or oxygen may have been present in sufficient quantities near the substrate interface to poison the shape memory effect.

The advantage of adding copper to the nickel-titanium system is apparent from Fig. 4, a plot of transformation temperatures vs. titanium content for film sections with a constant copper content of 7 at.\%. For titanium contents ranging from 47 to 51 at.\%, the transformation temperatures remained fairly constant, and are comparable to values reported for bulk Ni-Ti-Cu SMA's. ${ }^{28,29}$ In contrast, $M_{s}$ for a 49 at.\% titanium Ni-Ti bulk alloy falls to $-100^{\circ} \mathrm{C} .{ }^{13}$ The recoverable stress, $\sigma_{\mathrm{rec}}$, is also consistently high over the same compositional range, as seen in Table $\mathrm{I}$.

Figure 5 shows plan view TEM micrographs of the $\mathrm{Ni}_{43} \mathrm{Ti}_{50} \mathrm{Cu}_{7}$ film section in the low and high temperature phases. Thicker areas of the specimen were in the martensitic phase while 
thin regions were austenitic. Heat from the electron beam caused the entire specimen to transform to the austenitic phase, but spreading the beam and allowing the specimen to return to room temperature did not result in reformation of the martensite. Dislocations and precipitates were present in some of the grains, although most grains were predominantly defect and precipitate free. Precipitates appeared in the grain interiors as well as at the boundaries, which has been reported in other studies of $\mathrm{Ni}-\mathrm{Ti}$ and $\mathrm{Ni}-\mathrm{Ti}-\mathrm{Cu}$ films. ${ }^{7,20}$ It is not possible to establish whether the dislocations were the result of excessive residual stress, or artifacts from TEM specimen preparation. Grain sizes ranged from 0.2 to $0.3 \mu \mathrm{m}$, based on the TEM micrographs.

\section{CONCLUS:ONS}

Mixed-sputter deposition has proven to be a viable method for producing shape memory $\mathrm{Ni}-\mathrm{Ti}-\mathrm{Cu}$ films, providing the compositional flexibility necessary for optimization of SMA properties, and substrate curvature was shown to be an effective technique for characterizing SMA films. The Ni-Ti-Cu film properties, including transformation temperatures, martensitic yield stress, and recoverable stress, were found to be comparable to the properties of bulk alloys, and the addition of 7 at.\% $\mathrm{Cu}$ was shown to make the transformation temperatures less sensitive to titanium content. Films with 51 at.\% $\mathrm{Ti}$ have $\mathrm{M}_{\mathrm{f}}$ close to body temperature, making them ideally suited for medical applications. Once the shape memory effect has been optimized for a particular application, uniformity can be improved by increasing the distance between the targets and the substrate, or rotating the substrate during deposition.

\section{ACKNOWLEDGMENTS}

We would like to thank Ron Musket at LLNL for performing the chemical analysis, the XRay Optics group at Lawrence Berkeley Laboratory for use of their Tencor wafer curvature system, and Raychem Corporation for providing the NiTi standard. This work was conducted under the auspices of the U.S. Dept. of Energy by Lawrence Livermore National Laboratory, contract number W-7405-ENG-48. P. Krulevitch was partially supported by a National Science Foundation grant, No. ECS-9023714. 
${ }^{1}$ Engineering Aspects of Shape Memory Alloys, ed. T.W. Duerig, K.N. Melton, D. Stockel, and C.M. Wayman (Butterworth-Heinemann Ltd., London, 1990).

${ }^{2}$ Shape Memory Alloys, ed. H. Funakubo, translated by J.B. Kennedy (Gordon and Breach Science Publishers, New York, 1984).

${ }^{3}$ J.A. Walker, K.J. Gabriel, and M. Mehregany, Sensors and Actuators, A21-A23, 243 (1990).

${ }^{4}$ A.D. Johnson, J. Micromech. Microeng., 1, 34 (1991).

${ }^{5}$ K. Kuribayashi, T. Taniguchi, M. Yositake, and S. Ogawa, Mat. Res. Soc. Symp. Proc., 276, 167 (1992).

${ }^{6}$ K. Kuribayashi, S. Shimizu, T. Nishinohara, T. Taniguchi, M. Yoshitake, and S. Ogawa, Proc. 1993 IEEE/RSJ Int. Conf. on Intelligent Robots and Systems, Yokohama, Japan, IEEE 0-78030823-9, 1697(1993).

${ }^{7}$ M.H. Berkson, M.S. Thesis, Mat. Sci. and Min. Eng., University of California, Berkeley (1990).

${ }^{8}$ J.D. Busch, A.D. Johnson, C.H. Lee, and D.A. Stevenson, J. Appl. Phys., 68, 6224 (1990).

${ }^{9}$ K.R.C Gisser, J.D. Busch, A.D. Johnson, and A.B. Ellis, Appl. Phys. Lett., 61, 1632 (1992).

${ }^{10}$ S.Z. Hua, C.M. Su, and M. Wuttig, Mat. Res. Soc. Symp. Proc., 308, 33 (1993).

${ }^{11}$ S. Miyazaki and K. Nomura, Proc. IEEE Workshop on Micro Electro Mechanical Systems, Oiso, Japan, 176 (1994).

${ }^{12}$ K. Ikuta, M. Hayashi, T. Matsuura, and H. Fujishiro, Proc. IEEE Workshiop on Micro Electro Mechanical Systems, Oiso, Japan, 355 (1994).

${ }^{13}$ K.N. Melton in Engineering Aspects of Shape Memory Alloys, ed. T.W. Duerig, K.N. Melton, D. Stockel, and C.M. Wayman (Butterworth-Heinemann Ltd., London, 1990) p. 23.

${ }^{14}$ O. Mercier and K.N. Melton, Met. Trans. A, 10A, 387 (1979).

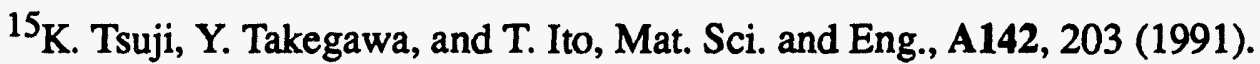

${ }^{16}$ Y. Furuya, M. Matsumoto, and T. Masumoto, Mat. Res. Soc. Symp. Proc., 246, 355 (1992).

${ }^{17}$ T. Saburi, T. Takagaki, S. Nenno, and K. Koshino, Mat. Res. Soc. Mtg. on Adv. Mats., Tokyo, Japan, 9, 147 (1989).

${ }^{18}$ L. Chang and D.S. Grummon, Scripta Met., 25, 2079 (1991).

${ }^{19}$ L. Chang, C. Hu-Simpson, D.S. Grummon, W. Pratt and R. Loloee, Mat. Res. Soc. Symp. Proc., 187, 137 (1990).

20L. Chang and D.S. Grummon, Mat. Res. Soc. Symp. Proc., 246, 141 (1992).

${ }^{21}$ B. Walles, L. Chang, and D.S. Grummon, Mat. Res. Soc. Symp. Proc, 246, 349 (1992).

${ }^{22}$ A.F. Jankowski, D.M. Makowiecki, M.A. McKernan, R.J. Foreman, and R.G. Patterson, SPIE Proceedings, X-Ray/EUV Optics for Astronomy, Microscopy, Polarimetry, and Projection Lithography, 1343, 32, (1990). 
${ }^{23}$ W.J. Moberly and K.N. Melton in Engineering Aspects of Shape Memory Alloys, ed. T.W. Duerig, K.N. Melton, D. Stockel, and C.M. Wayman (Butterworth-Heinemann Ltd., London, 1990) p. 46.

${ }^{24}$ R.W. Hoffman in Physics of Thin Films, 3, ed. G. Hass and T.E. Thun (Academic Press, New York, 1966) p. 211.

${ }^{25}$ W.A. Brantley, J. Appl. Phys., 44, 534 (1973).

${ }^{26}$ T.W. Duerig and C.M. Wayman in Engineering Aspects of Shape Memory Alloys, ed. T.W. Duerig, K.N. Melton, D. Stockel, and C.M. Wayman (Butterworth-Heinemann Ltd., London, 1990) p. 3.

${ }^{27}$ K.N. Melton and O. Mercier, Scripta Met. 12, 5 (1978)

${ }^{28}$ T.H. Nam, T. Saburi, and K. Shimizu, Mat. Trans., JIM, 31, 959 (1990).

${ }^{29}$ R.H. Bricknell, K.N. Melton, and O. Mercier, Met. Trans. A, 10A, 693 (1979). 
Table 1: Transformation temperatures, hysteresis width, and recoverable stress of Ni-Ti-Cu films from individual $2 \times 2 \mathrm{~cm}$ dies. Copper content is constant at 7 at.\%. Film sections with 41 and 44 at.\% Ti did not show shape memory behavior between 24 and $100^{\circ} \mathrm{C}$

\begin{tabular}{|c|c|c|c|c|c|c|}
\hline $\begin{array}{c}\mathrm{Ti} \\
(\mathrm{at \%})\end{array}$ & $\begin{array}{c}\mathrm{M}_{\mathbf{s}} \\
\left({ }^{\circ} \mathrm{C}\right)\end{array}$ & $\begin{array}{c}\mathrm{M}_{\mathrm{f}} \\
\left({ }^{\circ} \mathrm{C}\right)\end{array}$ & $\begin{array}{c}\mathrm{A}_{\mathbf{s}} \\
\left({ }^{\circ} \mathrm{C}\right)\end{array}$ & $\begin{array}{c}\mathrm{A}_{\mathrm{f}} \\
\left({ }^{\circ} \mathrm{C}\right)\end{array}$ & $\begin{array}{c}\text { Hyst } \\
\left.{ }^{\circ} \mathrm{C}\right)\end{array}$ & $\begin{array}{c}\sigma_{\text {rec }} \\
(\mathrm{MPa})\end{array}$ \\
\hline \hline 51 & 53 & 36 & 47 & 62 & 10 & 330 \\
50 & 44 & 20 & 35 & 56 & 13 & 210 \\
48 & 48 & 20 & 32 & 59 & 12 & 310 \\
47 & 44 & 22 & 34 & 55 & 12 & 295 \\
44 & -- & -- & -- & -- & -- & -- \\
41 & -- & -- & -- & -- & -- & -- \\
\hline
\end{tabular}




\section{Figures}

Figure 1. Diced 4" wafer ( $2 \times 2 \mathrm{~cm}$ dies) showing relative position of sputtering sources. Shading indicates the degree of the shape memory effect (darker shades = strong effect, unshaded $=$ no shape memory effect in temperature range tested). Hatched dies were not tested.

Figure 2. Stress vs. temperature for four dies, measured by substrate curvature. Two measurements are shown for the die with a $\mathrm{Ni}_{42} \mathrm{Ti}_{51} \mathrm{Cu}_{7}$ film, one of which followed 25 additional thermal cycles between 24 and $100^{\circ} \mathrm{C}$.

Figure 3. Generic stress vs. temperature plot from curvature data.

Figure 4. Transformation temperatures and hysteresis width for Ni-Ti-Cu films vs. titanium concentration. Copper concentration is constant at 7 at.\%.

Figure 5. Plan view TEM micrographs from the $\mathrm{Ni}_{43} \mathrm{Ti}_{50} \mathrm{Cu}_{7}$ film section. Martensitic phase (top), and austenitic phase (bottom). 


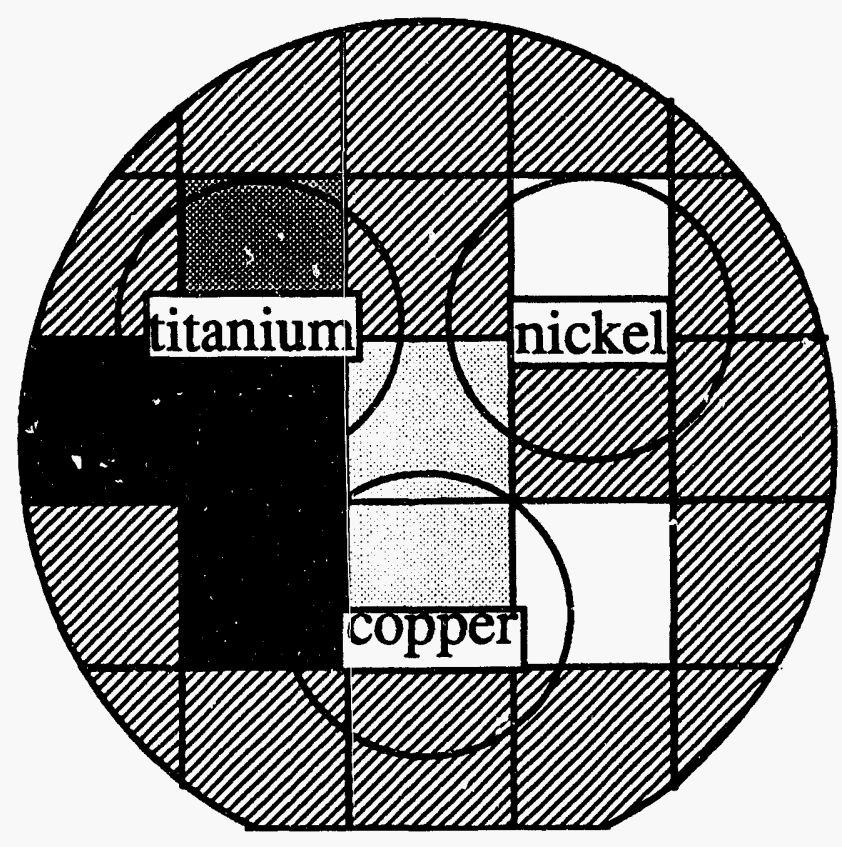

Figure 1. 


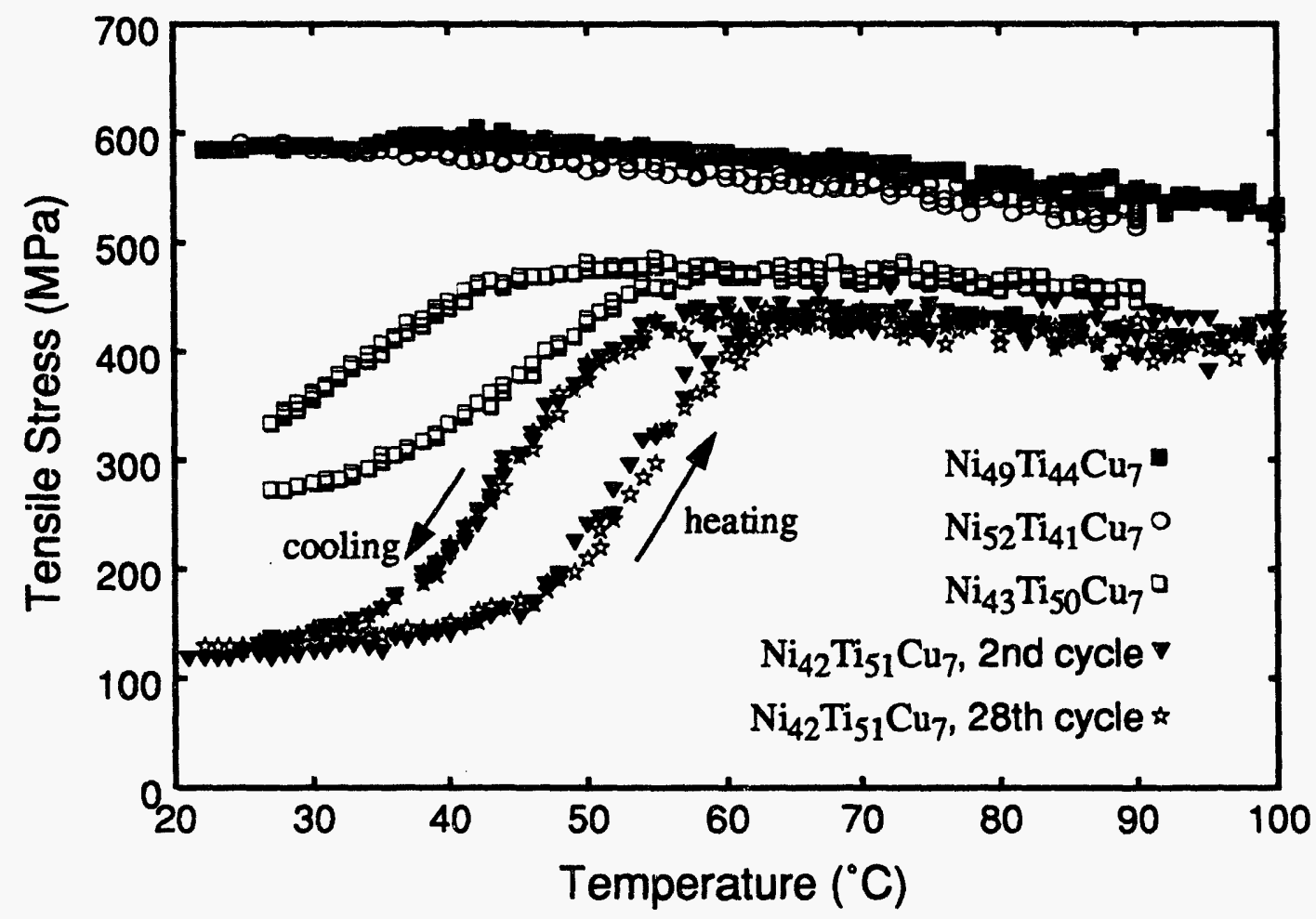

Figure 2. 


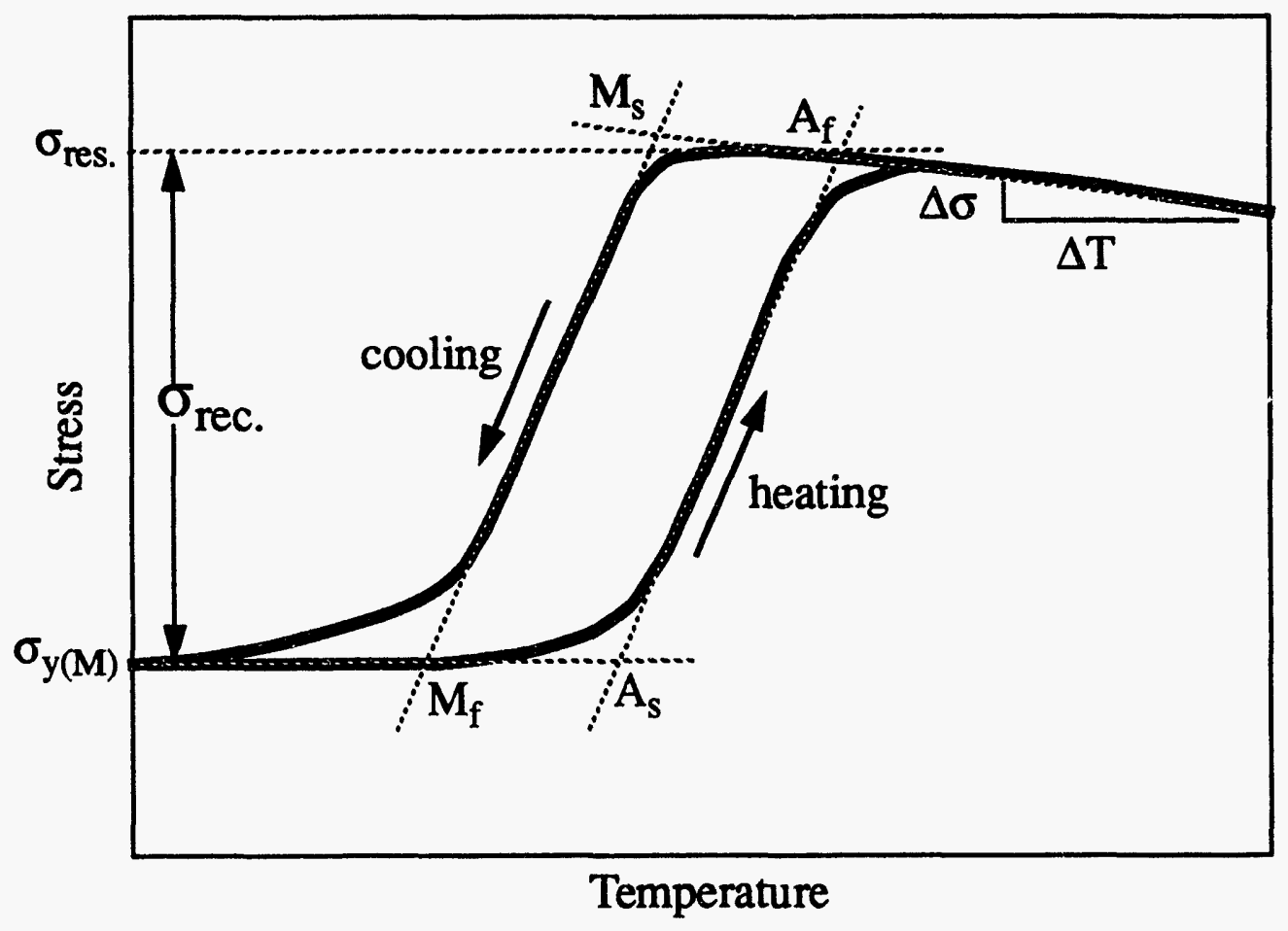

Figure 3. 
Krulevitch et al. "Mixed-Sputter Deposition of Ni-Ti-Cu Shape Memory Films"

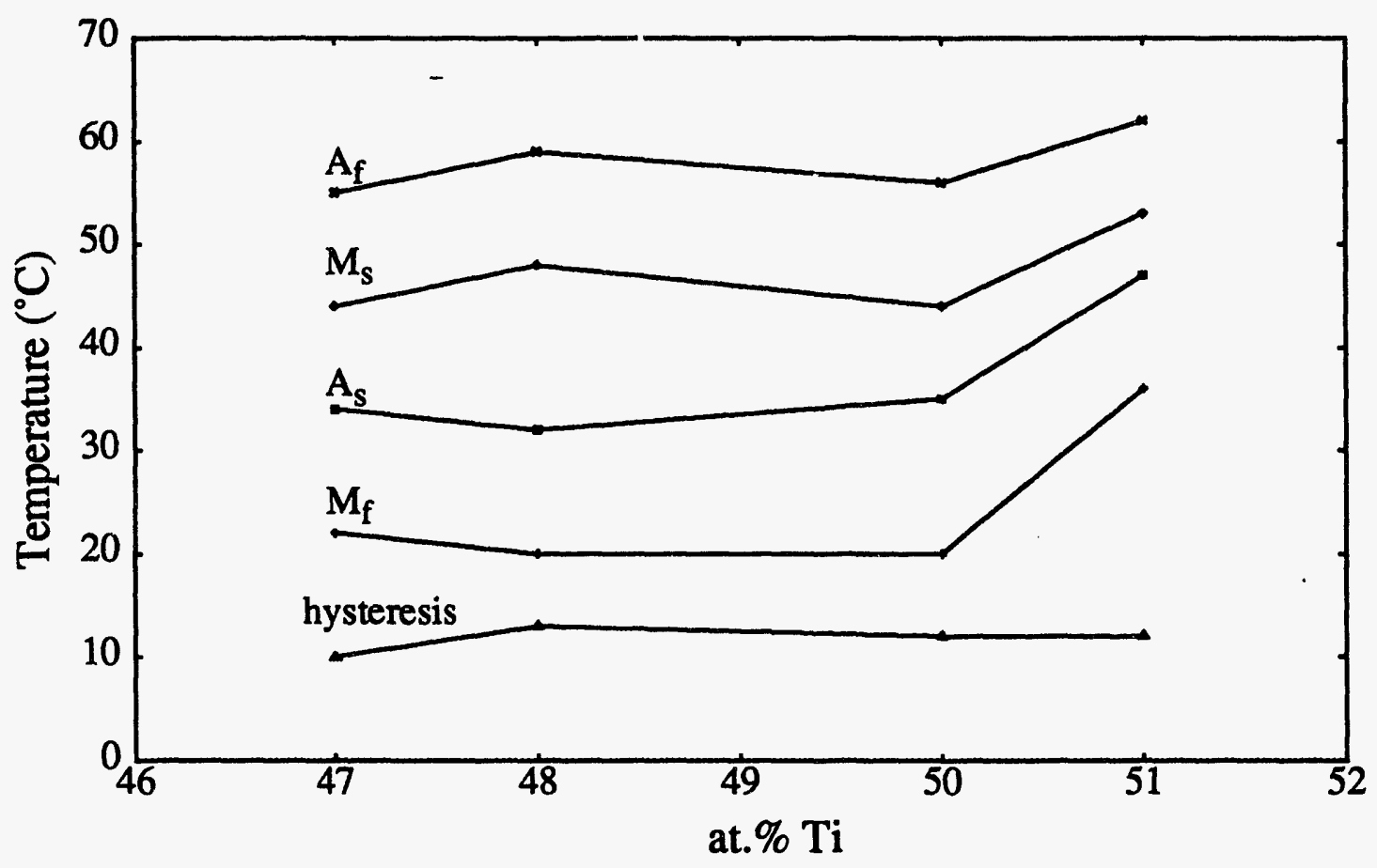

Figure 4 
Krulevitch et al. "Mixed-Sputter Deposition of Ni-Ti-Cu Shape Memory Films"
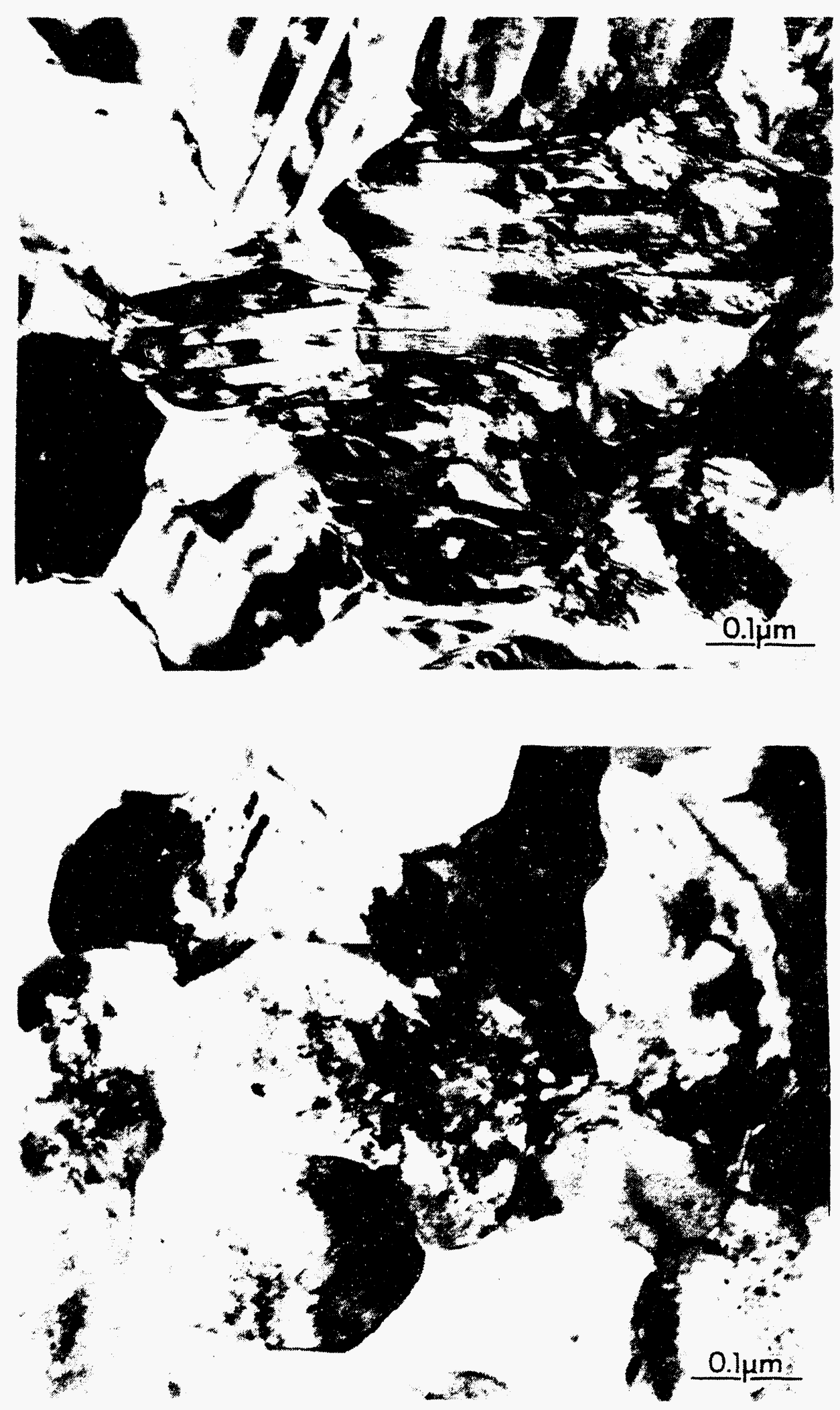

Figure 5 

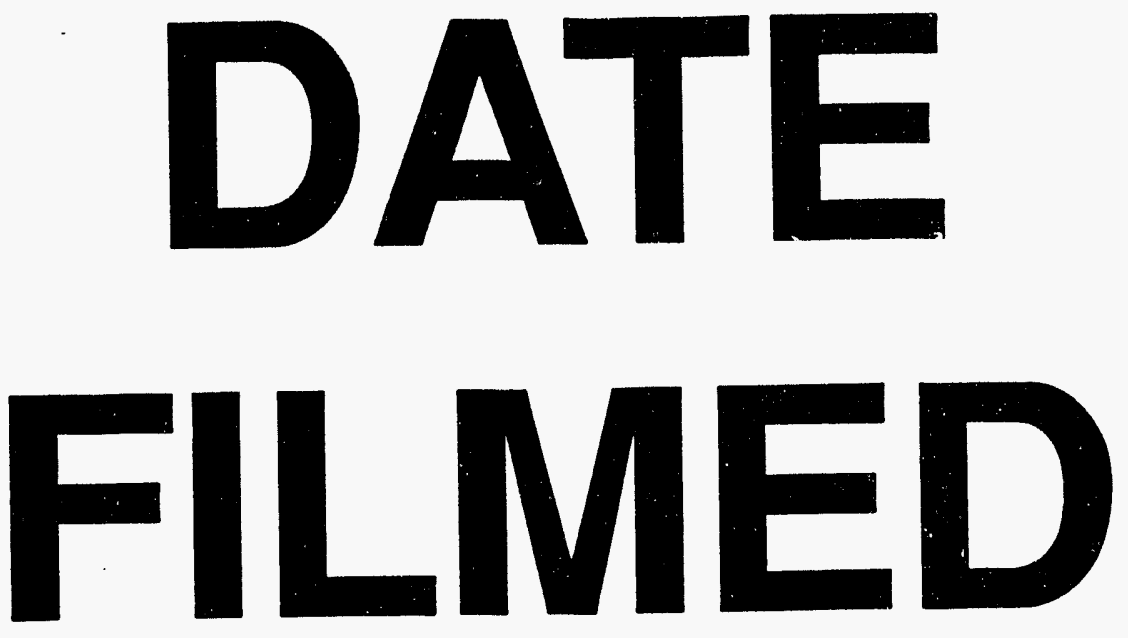

$10 / 7 / 94$
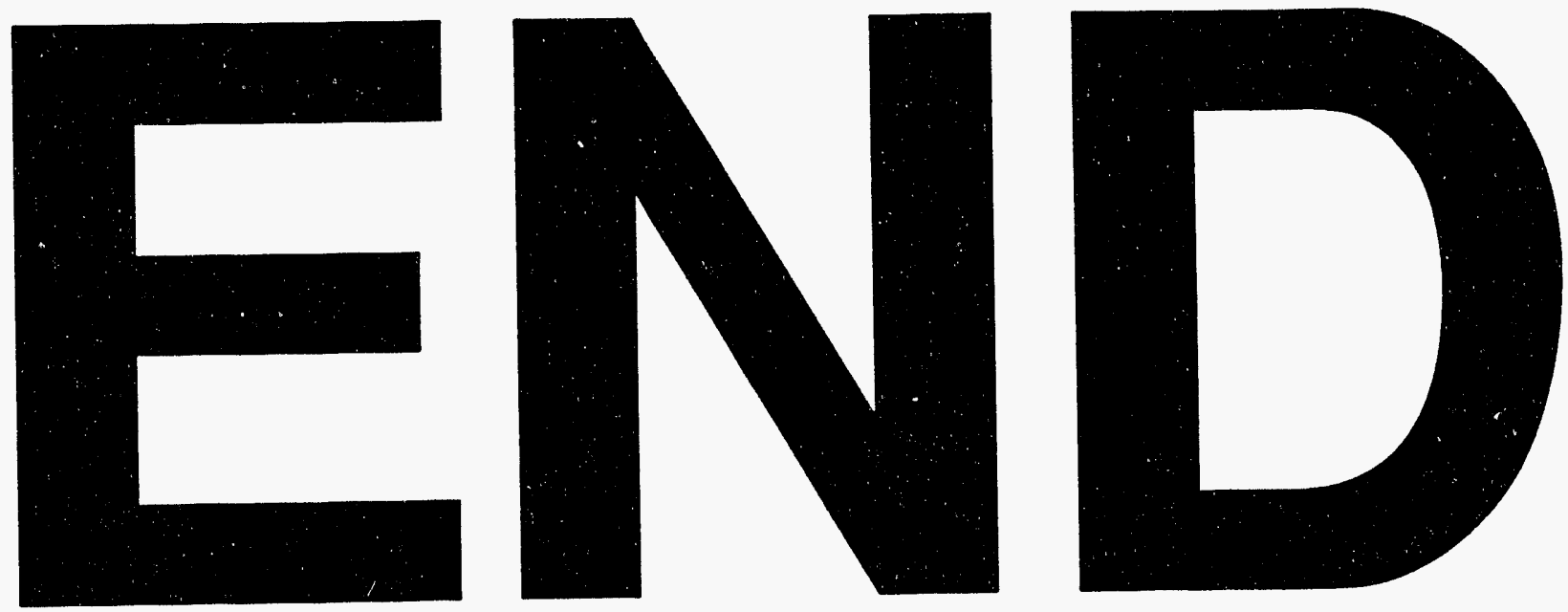


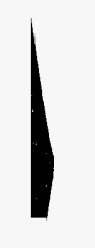

